\title{
Moving Closer to the Audience: Watching Football on Television
}

\author{
Cornelia Gerhardt \\ Sarlaand University \\ c.gerhardt@mx.uni-saarland.de
}

\begin{abstract}
This article aims to describe specific practices of television spectators based on recordings of English families and friends while watching football on television. Their conversations and the talk and events on television are transcribed and analysed with interactional sociolinguistic and conversation analytical methodologies.

By doing 'watching football on television', the spectators constitute themselves as a community of practice. Their strategies include direct address of the television (i.e. the commentator or one of the protagonists of the game) and signalling of independent knowledge and emotions to construct their identities of football fan and expert. Conflict between these two identities may become instantiated in the talk.

At times, the spectators mutually negotiate the participant role 'party to the talk at home' for the television. This is done by furnishing second pair parts to the commentators' adjacency pairs. Also, it includes respecting the commentators' turns. Having spent countless hours watching football on television, the spectators manage to carefully construct their talk around the commentators' so that one single, coherent conversation emerges.

The practices show how the participants as watchers strive to become part of the spectacle using the television as a bridge to the game itself.
\end{abstract}

\section{Introduction}

One thread with which one can attempt to describe the development of reception or audience studies is a move from the primary media text to the audience. This is mirrored by the abandonment of the concept of an (often passive, helpless) ideal spectator to the 
discovery of diverse audiences who actively negotiate their interpretations of media discourse.

The beginning of audience studies can be traced to the 1920s and 1930s when the massculture thesis emerged. The audience was seen as a mass of alienated subjects who could be controlled by the media (cf. the Frankfurt School, Adorno and Horkheimer, 1947). The 'effects' or 'hypodermic needle' model assumes that a message, be it for political propaganda or sales promotion, can be 'injected' into the population. However, when audience studies began to examine the workings between mass media and public opinion, it soon emerged that a simple stimulus-response model did not suffice. (Lazarfeld et al., 1944) One ensuing approach, the uses and gratifications model, already stresses that different parts of the audience use media in different ways to gratify their social and psychological needs (e.g. Winick, 1963).

The audience as vulnerable children, another strand of long standing in audience studies, is still popular today, as exemplified by the debates following the Columbine murders or Erfurt, Germany. In both cases, high school students who played violent video games seemingly transposed the mechanisms of these games into real life. Early examples in which the dangers especially of 'new' media are depicted describe the harmful influences of comic books on children. (Wertham, 1955; Hoggart, 1957) Again, the audience is perceived as helpless, passively absorbing content. This was perhaps partly prolonged in feminist studies where women were described as the passive element constructed by male gaze (Mulvey, 1975 with a psychoanalytic approach) or as having to be rescued from or enlightened about their media consumption. (Radway, 1984)

The works of British cultural studies (Hall, 1980; Morley, 1980) represent a milestone in the move away from the audience as passive victims. According to Hall, media texts are 'encoded' by the producers and later 'decoded' by the audience. Although there is a preferred reading of the texts, the audience can also resist this reading or find a middleground between accepting some of the values proposed and defying others. For Fiske (1987), following de Certeau (1980), audiences make room for their own interpretations in the predominant power frameworks represented by the media.

Audiences had finally become active. The image of an ideal spectator based on a sender-message-receiver model shattered to give way to qualitative, empirical studies of the diverse readings of different social groups. Methodologies such as interviews, retellings, focus groups, sorting tasks or participant observation were introduced to account for the various readings (e.g. Ang, 1985; Morley, 1980; Livingstone, 1990).

In this paper, I will continue in this strand by moving even closer to the audience and the reception process. As Staiger writes:

reception studies research cannot claim to say as much about an actual reading or viewing experience by empirical readers or spectators as it might like. Several factors intervene between the event and any possible sense data available for its study... Reporting, whether through a crafted ethnographic interview or a published review, is always subject to the problem of retrieval,... (Staiger, 1992: 79-80). 
Some of the issues put forward by Staiger can be evaded by a close reading of the talk naturally occurring during the reception. The spectators are not "reporting" their viewing experience, but their talk during that experience opens a window on the reception process. No potentially skewing memory is involved. Instead, there is immediacy between the data and the reception. Thus, the move from studying "interviews" and "reviews" to analysing the conversations during the viewing process represents a move towards the "actual reading or viewing experience".

Turning to linguistics, Scollon laments that "there have been virtually no studies of the social practices by which the discourses of the media are appropriated in common face-toface interactions". (1998: vii) I will study this appropriation with the help of the ATTAC (Analysing The Television Audience's Conversation) corpus, which consists of recordings of different groups of people watching football on television. To undertake a close analysis of the talk in this specific form of setting, I will use findings, concepts, and methodologies from ethnographic conversation analysis and interactional sociolinguistics. In particular, the concepts of the 'watch' (Scollon, 1998), 'community of practice' (Wenger, 1998; Eckert and McConnell-Ginet, 1992) and 'participant role' (Goffman, 1981; Levinson, 1988) will be applied to the data.

In a similar endeavour, Beck (1995) filmed students in the common room of a dormitory. Taking up Fish's notion of an 'interpretive community', (1980) she shows how a group of Giants' fans marks itself as such by "the display of knowledge of shared terms, the overt identification of allegiance to the New York Giants, and the participation in an ongoing commentary of the game... from a 'Giants' fan's perspective". Linguistically, her interpretation is based on the use of jargon ("footballese,") $1^{\text {st }}$ person plural pronouns, interjections, and extra-/paraverbal behaviour such as applause. She demonstrates how this group defines itself in opposition to other students, non-Giants' fans who also join to watch games. Lacking in her study, though, is the analysis of the interplay between the talk of the fans and the primary media text.

Matthewson (1992) undertook a close reading of the talk of female students watching two different soap-operas and a quiz show. She found utterances "to" and "with" the television. She concluded that the television "may substitute for conversation, licensing lapses, but at other times is no bar to spans of normal conversation". (1992: 29) Her study also does not take the language on television into account.

Liebes and Katz (1990) undertook a cross-cultural study of the reception of the TV series Dallas. Small groups of friends and neighbours watched Dallas together in the home of one of the participants. Focussing on the talk during the viewing, however, seemingly only some of data were transcribed from tapes while others were based on field notes (cf. Liebes and Katz, 1990: 31 and 41). Also, the conversations were coded using rough categories such as 'referential' or 'critical' and no close turn-by-turn analysis of the interactions was undertaken. (Liebes and Katz, 1990: 32ff) The authors, too, realise that this procedure is problematic: "A recoding of critical statements in smaller units and in more subdivisions produced a much larger number of critical statements than before. The earlier coding is biased towards the referential..." (Liebes and Katz, 1991: 33) 
For the DFG project "Über Fernsehen sprechen" (Holly et al, 2001; Baldauf, 1998; Klemm, 2000), the interaction of German families watching television in their homes was taped. For this project, both the talk of the viewers and the talk/events on television were transcribed. Of special interest here is Hepp, who studies the reception of a football game. He illustrates how a father and his son construct a common (gendered) reception situation by co-commenting the game. (1998: 208)

Returning to my project, for the ATTAC Corpus, natural conversation among home viewers of televised football games was recorded on video. Later the talk was transcribed using the conventions at the end of the paper. The groups consist of male-only dyads and mixed-sex groups of friends and families. Some of them live together and others met solely for the purpose of watching a game. The age of the participants ranges from 14 months to over 70 years. The recorded are all middle-class British English speakers of non-immigrant parentage. They generally side for the same team. The games recorded are all internationals which were part of the World Cup 2002 in Japan/Korea.

The data recorded differ along two parameters. As is obvious to any sports aficionado, the first is the game itself: the later in the tournament, the more excitement. As the advancement of the teams in the tournament is immediately at stake, games at the knock-out stage are generally viewed with more emotion and involvement than those at the beginning of the group stage. Also, the pairings play an important role. Games with England and, to a lesser extent, other great football nations (e.g. Brazil, Germany) are, from the outset, greeted with more interest than e.g. Japan - Russia. However, any game may turn out to be exciting and acquire significance through the events in the game itself (e.g. remarkable goals, doubtful refereeing decisions etc.). The second parameter is the viewers. The data suggest that there is much more talk between interlocutors who have been especially invited over to watch football than between the families who live together in the first place.

A short account of the games and groups of people which are used as examples in this article will be given in the following. With the help of the abbreviations (such as AE1C) the readers can trace the context of the conversations. The videos AE1C and AE2C representing the $1^{\text {st }}$ and $2^{\text {nd }}$ half of Argentina - England were recorded at the home of a former referee Henry. He invited one of his old colleagues, Darrell, and both are later joined by Henry's wife Wilma. All three are over 70 years of age. The game was part of the group stage and England won 0:1. The $1^{\text {st }}$ half of England - Brazil, EB1A, is a video from the home of a young family: Andrew, Ursula, and their 14-months-old toddler Laurie. The game was a quarter-final and represents one of the most noted games of the World Cup, which England lost 1:2. EB2R, the $2^{\text {nd }}$ half of the aforementioned game England - Brazil, and BB1R, the $1^{\text {st }}$ half of Brazil - Belgium, are recordings of a family with Gerard, Jodie and their teenage son Benjamin. Brazil won 2:0 and progressed to the quarter final. JR1T, the $1^{\text {st }}$ half of Japan - Russia, a group stage game which was won 1:0 by Japan, is a video of two friends, Tom and Frank, who are in their thirties to forties and work in London. This game, by itself, aroused the least interest at the outset and was only watched because it was part of the World Cup. 


\section{Talking and watching television}

Generally, the conversations in front of the television resemble Goffman's 'open state of talk': "participants have the right but not the obligation to initiate a little flurry of talk, then relapse back into silence". (1981: 134) However, over long stretches of talk, conversation with the television running does not differ from other conversations. But for lack of space, I could present various pieces of prolonged talk in which no trace of the presence of the television can be found. This shows, unsurprisingly, that the audience is not an empty container in which messages can be poured, but that it consists of active social agents whose lives do not come to a halt when they are exposed to a mass medium.

According to Scollon, the television in households is most often assigned a similar communicative function as wall paper: "as unanalysed and unattended background decoration". (1998: 151) The following analysis will illustrate that this is decidedly not the case in the football corpus, as the participants gathered for the purpose of watching television (for exceptions see below).

Although the conversations recorded are often non-distinct from those at, e.g., a dinner table, a couple of view-signs (Scollon, 1998: 93) make the relation to the television explicit: the postures of the viewers with their fronts facing the television show that they are attending to the game. The gazes of the participants also reveal that they are simultaneously watching television. They tend to look at the television turning their eyes (and bodies) towards their co-conversationalists only for split seconds. In Scollon's terms, the audience as 'watchers' together with the game as 'spectacle' form 'a watch': "any person or group of people who are perceived to have attention to some spectacle as the central focus of their (social) activity". (1998: 92) In differentiating between "watchers" and the 'spectacle', Scollon stresses that the primary interaction is within those groups and not between the television as sender and the spectators as receivers. Also, "there are limits on feedback [between those two groups] which are either socially or technologically grounded". (Scollon, 1992: 91)

Two other phenomena underline the finding that the viewers are following the games closely despite their ongoing interaction with each other: the triggering of side-sequences and topic shifts due to events on television (cf. Klemm, 2001: 127).

\section{Example 1: AE1C close one}

$\begin{array}{lll}1 & \text { Henry } & \text { Pierluigi Collina is referee today. }= \\ 2 & \text { Darrell } & \text { [=yes.] } \\ 3 & \text { Henry } & \text { [there's] absolutely no coincidence, }= \\ 4 & \text { Darrell } & \text { =yeah, } \\ 5 & \text { Henry } & \text { in his being appointed to this game. } \\ 6 & & (1.9) \\ 7 & & \text { he's uh- } \\ 8 & & \text { OUH, } \\ 9 & & (1.2)\end{array}$


10

11

12

13

close one,

right across the goal,

talking to some of our premier league referees, =

$=$ they have nothing but admiration for him,

Side-sequences (Jefferson, 1972) generally occur when the event on television happens in the middle of a turn by one of the conversationalists. Lines $8-11$ represent a side-sequence in this example. In line 7, the hesitation marker "uh-" may already indicate that something noteworthy is happening on television. Henry seems distracted from finishing his utterance, though still holding on to his turn with the help of that filled pause. The break-off displays the speaker's shift of attention from his talk to the television. At the end of the sidesequence (line 11,) he signals with a slight rise at the end of his intonation unit that he means to continue. Without any apparent pause $(<0.2$ seconds, ) he carries on talking about Pierluigi Collina. These side-sequences, which are common in the corpus, show that despite ongoing conversation the events on television are closely followed and analysed as to their significance.

The second phenomenon is that events on television trigger longer sequences by initiating a new topic. The context is often that the interlocutors have just finished discussing another topic.

Example 2: JR1T it's these light balls

\begin{tabular}{|c|c|c|}
\hline 1 & Tom & yeah. \\
\hline 2 & Frank & $\{$ laughs\} \\
\hline 3 & & $(0.9)$ \\
\hline 4 & Tom & OUH- \\
\hline 5 & & $(1.0)$ \\
\hline 6 & & ah- \\
\hline 7 & & $(6.2)$ \\
\hline 8 & Frank & it's these light balls I think \\
\hline 9 & & they skipe, \\
\hline 10 & & too often, \\
\hline 11 & Tom & \{nods\} \\
\hline
\end{tabular}

The stretch above illustrates a transition period between two topics. Lines 1 and 2 represent the closing sequence to a longer stretch on horse racing. Lines $4-6$ constitute Tom's reaction to a scene on television. Frank provides an explanation for the scene in lines 8 10. Both continue talking about the new balls for another minute.

However, in conversations without television, side-sequences and topic shifts due to contextual changes are also common (cf. Tannen, 1984). They alone do not differentiate talk accompanying television from other talk.

These prolonged conversations between the viewers at home imply that both they and the commentators on television talk at the same time over longer periods. In conversation 
in general, however, "at least, and no more than, one party speaks at a time in a single conversation". (Schegloff and Sacks, 1973: 293) Taking this rule for granted, the following implications arise out of this deviant behaviour of the conversationalists: either, the television is not seen as 'party" to the conversation, in other words, there is more than "a single conversation," or a different organization of turn-taking prevails in this setting.

The obvious answer seems to be that a technical apparatus like a television set cannot represent a party in a conversation and that the (speech) events on television are separate matters, 'watchers' and 'spectacle' in Scollon's terms. However, the following excerpts from the ATTAC corpus suggest that this is not strictly the case.

\section{Direct address}

Direct address between the television and the parties at home is quite common in the corpus. In the following, the television commentator speaks to the fans at home directly:

Example 3: EB1 bacon and eggs

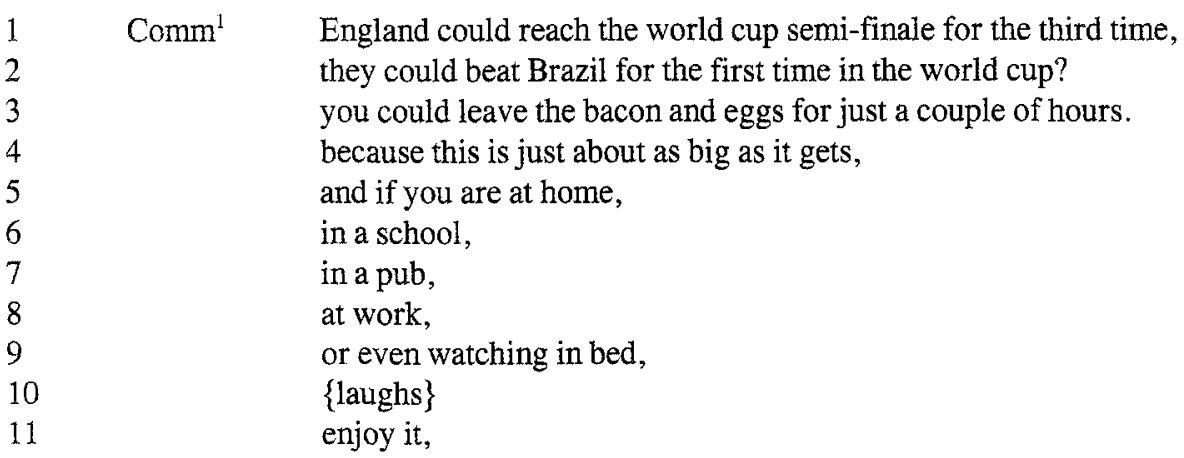

The $2^{\text {nd }}$ person pronoun, ambiguous as to whether singular or plural, seems to encompass all possible spectators as the list (lines 5 -9) suggests. Every viewer should feel personally addressed. The commentator is trying to reach out into the locations of his viewers. By connecting this important game (quarter-final England - Brazil) and the everyday life of the viewers, he simultaneously links the significant and the mundane, inviting the audience to become part of this world-wide spectacle.

More noteworthy, though, is the opposite direction, namely that the viewers at home address a person on television directly. Especially in watching sports, spectators like to shout at the screen to cheer or coach their team. Matthewson concludes: "People like to talk to the television. When they do so, however, they are not usually doing so for their own or the television's benefit, but rather their utterances are directed at other viewers". (1992: 34) Also, Baldauf (2001) found only cases in which the conversationalists showed emotional detachment to the incidents on television and staged their utterances for the 
amusement of the co-viewers.

In the football corpus here, however, in many cases, the talk directly addressing a person on television consists simply of cheering on the teams.

Example 4: AE1C go on then

$\begin{array}{lll}1 & \text { Wilma } & \text { GO ON THEN, } \\ 2 & & (0.5) \\ 3 & & \text { [COME ON LAD,] } \\ 4 & \text { Henry } & \text { [HE- IT'S] IN AGAIN }\end{array}$

In examples 5 and 6 , the viewers at home take on the role of the team manager as if they were coaching their team from the sidelines.

Example 5: AE1C the one of you

$\begin{array}{lll}1 & \text { Comm } & \begin{array}{l}\text { Campbell, } \\ (0.4) \\ 2\end{array} \\ 3 & & \text { to Veron, } \\ 4 & & (2.0) \\ 5 & \text { Darrell } & \text { THE ONE OF YOU, } \\ 6 & \text { Henry } & \text { yeah. } \\ 7 & & (0.7) \\ 8 & \text { Darrell } & \text { he messed up like Mills the other day. }\end{array}$

Here, Darrell addresses two of the players telling them to play the ball (line 5). In the following segment, England leads 1:0 against Brazil and Ronaldo has just had a good chance for a goal. So Andrew seemingly wants to remind the players of their central task (line 1).

Example 6: EB1A keep defending

1 Andrew
2 COEP DEFENDING,

The transcriptions suggest that the talk directed at the protagonists on television is often marked by a rise in volume and high pitch. By signalling in this manner to their interlocutors that they are not directing their talk to them, they, at the same time, seem to be trying to bridge the gap between the people on television and their living rooms. Sometimes they seem oblivious to their surroundings and the other spectators, simply giving vent to their feelings.

However, the next-turns by the other viewers illustrate that the behaviour is often echoed by them in that they also start shouting at the screen (cf. Henry in example 4). Also, these utterances are often ratified as in example 5 , line 6 "yeah". Thus, directly addressing 
a protagonist in the game seems to serve multifarious functions amongst them, as I will later suggest, group-building.

\section{The television as party to the conversation}

Moving from direct address, which can already be interpreted as a sign for a joint conversation, I want to argue in the following that at times the television is treated as party to the talk at home so that the two strands of talk mingle to form a single, coherent conversation.

Example 7: EB2R is it Gilberto Silva?

\begin{tabular}{|c|c|c|}
\hline$\frac{1}{2}$ & Pundit & $\begin{array}{l}\text { looks like (?) } \\
\text { is it Gilberto Silva? } \\
(2.0)\end{array}$ \\
\hline $\begin{array}{l}4 \\
5\end{array}$ & Gerard & $\begin{array}{l}\text { I don't know, \{shakes his head }\} \\
\text { (1.1) }\end{array}$ \\
\hline $\begin{array}{c}6 \\
7\end{array}$ & Comm & $\begin{array}{l}\text { the referee, } \\
(0.5)\end{array}$ \\
\hline 8 & & $\begin{array}{l}\text { flashed a card. } \\
(1.3)\end{array}$ \\
\hline 10 & & and I'm just wondering [he \\
\hline 11 & Benjamin & $a$ \\
\hline
\end{tabular}

The transcription above is part of a longer stretch of talk in which replays are shown, as it is unclear what happened on the pitch. The particularity of this excerpt is that Gerard, at home, answers a question (line 4) asked by the pundit on television (line 2).

Levinson writes about adjacency pairs like the question-answer sequence of the example: "Having produced a first part of some pair, current speaker must stop speaking, and next speaker must produce at that point a second part to the same pair. Adjacency pairs seem to be a fundamental unit of conversational organization". (Levinson 1983: 304) In example 7, this "fundamental unit" is constructed by the commentator on television formulating the first part and by a viewer at home producing the second pair part. Incidentally, the question is never answered by the other commentator, so that the two conversations here synchronize completely to form one single conversation in which everybody, both the viewers at home and the journalists, is expressing their mutual puzzlement (lines $10-11$ ).

Twelve seconds later in the game ${ }^{2}$, again the two strands of conversation come together: 
Example 8: EB2R he showed the red Trevor

\begin{tabular}{|c|c|c|}
\hline $\begin{array}{l}1 \\
2\end{array}$ & Comm & $\begin{array}{l}\text { and- } \\
\text { u- unless I'm very much mistaken, } \\
\text { he showed [the red] Trevor. }\end{array}$ \\
\hline 4 & Gerard & [yes,] \\
\hline 5 & & $(0.8)$ \\
\hline 6 & & yes. $=$ \\
\hline 7 & Pundit & $=$ well at the moment, \\
\hline 8 & & there's no movement. \\
\hline 9 & & but he's shown it, \\
\hline 10 & & he's gotta go. \\
\hline 11 & & $(2.0)$ \\
\hline $\begin{array}{l}12 \\
13\end{array}$ & Comm & well there is the Brazilian coach, \\
\hline 14 & Benjamin & look at that. \\
\hline 15 & & (1.5) \\
\hline 16 & & yeah, $=$ \\
\hline 17 & Gerard & $=$ that's what it is, \\
\hline
\end{tabular}

The commentator is still not completely sure what happened in the game signalling it with the cutoff in line 1 "and-," the hesitation at the beginning of line 2 " $\mathrm{u}-$," and the epistemic phrase "unless I'm very much mistaken". After expressing his uncertainty and vagueness as to the truth-value of his proposition, in line 3 he finally states: "he showed the red Trevor". The term of address, Trevor, is used by the current speaker (the commentator) to select the next speaker (Trevor, the pundit). (Sacks et al, 1974: 704) In using the term of address and uttering it within one intonation unit i.e. within one information unit (Cruttenden, 1986; Chafe and Danielewicz, 1987), his uncertainty is again underlined. He seems to beckon for the co-commentator to assert his statement. However, the pundit does not come forth with the desired confirmation and again Gerard stands in corroborating the commentator's view (lines $4-6$ ). Hence, once more a fundamental unit of conversation is constructed between a viewer at home and a person on television.

In line 14 , once the commentator has signalled the end of his turn with final falling intonation, Benjamin self-selects as next speaker (Sacks et al, 1974: 700) and continues the talk at home. Although the scene Benjamin refers to with "look at that" is already on, when the commentator is still finishing his turn (in line 13), no overlap between the talk on television and the talk at home occurs. The viewers at home respect the commentators' turns and wait to get the floor. Hence, just like in example 7, the participants in front of the television manage to weave their conversation into the ongoing talk between the commentator and the pundit, so that a single conversation emerges.

This seamlessness appears to be favoured by the general agreement between all four participants: they are all uncertain what happened (even the Brazilian coach looks equally mystified) and they are trying to work it out while watching the replays. 
In the following, however, there are contrasting views on how a scene should be interpreted.

Example 9: EB2R I don't think so

$\begin{array}{lll}1 & \text { Comm } & \begin{array}{l}\text { Rivaldo, } \\ 2\end{array} \\ 3 & \text { IS }^{3} & \{\text { whistle\} } \\ 4 & \text { Comm } & \text { free kick to Brazil. } \\ 5 & \text { Gerard } & \text { I don't think so. } \\ 6 & & (0.6) \\ 7 & \text { Comm } & \text { Campbell and Scholes, } \\ 8 & & \text { both made the challenge. }\end{array}$

In this stretch of talk, line 5, Gerard directly refutes the claim put forth on television (either by the commentator or by the whistling of the referee). Again, Gerard manages to insert his protest smoothly with no overlap. Also, the commentator seems to answer him by giving the reason for the decision.

Surprisingly often, the spectators seem to be able to accurately forecast pauses in the talk of the commentators on television. This allows them to insert their talk in the gaps. Having internalized the rules of football commentary during countless hours of watching games, they seem to be able to read the game and the accompanying talk. Two examples from a different game shall suffice to illustrate that this is not an idiosyncrasy or a special gift in Gerard's family.

The following stretch of talk is conspicuous by its number of latchings. Wilma, Henry's wife, has only just arrived so that it would be impolite not to talk to her. On the other hand, the talk on television needs to be oriented to at the same time.

\section{Example 10: AE2C wanna sit down}

\begin{tabular}{|c|c|c|}
\hline 1 & Comm & but it was Ashley Cole covered. $=$ \\
\hline 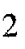 & Henry & $=$ wanna sit down? $\{$ to Wilma $\}$ \\
\hline & & [maybe] have lunch afterwards? = \\
\hline & Comm & [Aimar,] \\
\hline & & $=$ Ortega $=$ \\
\hline & Wilma & $=$ yeah yeah \\
\hline & & $(5.0)$ \\
\hline
\end{tabular}

Besides the overlap in lines 3 and 4, Henry and Wilma's talk squeezes into the gaps left by the television commentary. Like pieces of a puzzle that touch, the two strands latch on to each other. Henry, in line 2, latches on to the commentator's turn. In line 3, he manages to finish so that the commentator's talk latches on to his ending. Wilma finally, in line 6, latches her talk on to the commentator's again. Although here no single conversation is 
produced as both parties talk about different subjects, the effect of the conversationalists striving to respect the turns by the commentator is still visible.

A final example is the following. At this point, only lines $9-14$ are of interest. They illustrate how Henry is able to predict felicitously a longer gap which he can fill with his talk. Almost immediately ( 0.4 seconds) after the comments on the foul (lines $4-7)$, Henry starts talking about Aimar, a player who had just replaced Veron. Being "an attacking player" he is also the one who "had to be" fouled by Butt. Knowing the rules of football and football commentary, Henry predicts successfully that he can use the time that the players need to get ready for the free kick for a longer turn.

Example 11: AE2C foul by Butt

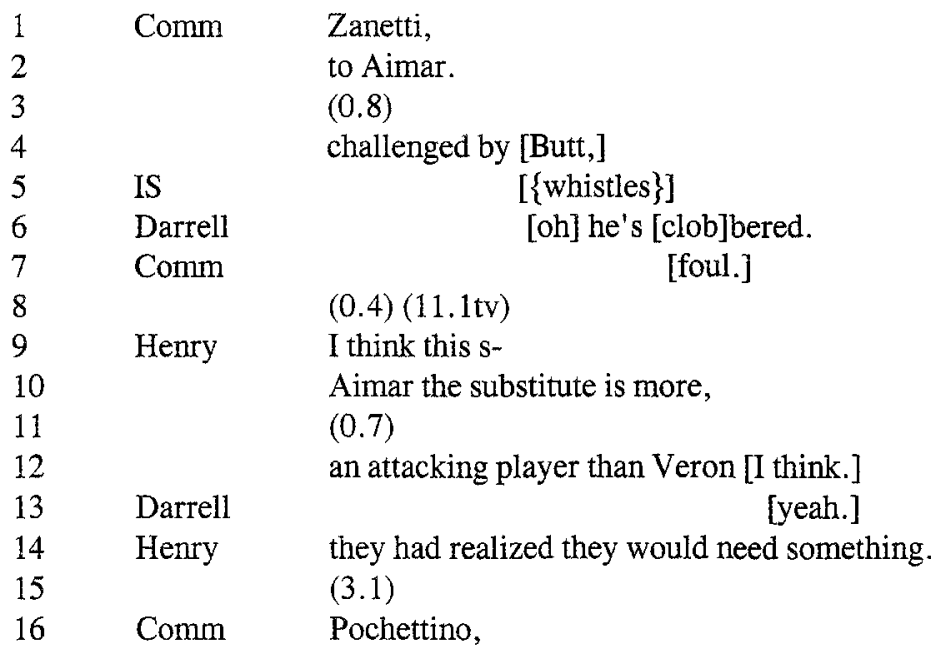

A final point regarding the synchronization of the talk at home with the commentary on television: in the transcripts with Andrew, Ursula and Laurie, the toddler, these instances do not occur. Andrew is the only one who is really following the game. Ursula is also watching, but in a more detached way. Furthermore, Laurie acts her age, which makes her a constant source of disturbance: she stands in front of the television; she climbs on her father's back; she "talks;" she fetches books and toys, which have to be explained; etc.

To summarise, the excerpts from the corpus suggest that the television, i.e., the commentators, is at times treated like any other interlocutor. The spectators address them directly. Together, they construct adjacency pairs. In addition, the viewers at home respect the turns taken by the journalists. They manage to project the possible completion points of the commentators' turns (both from their knowledge about talk in general, football, and football commentary in particular) allowing for such co-construction of talk.

For the turn-taking mechanisms this shift in 'footing' (Goffman, 1981; Levinson, 1988) signifies that the television gains dominance. The audience at home has to accommodate 
their talk. Hence, in the end, the participants by making the television party to their talk, by merging the strands, really make themselves party to the talk on television.

\section{Negotiating participant roles and identities}

In the following I argue that the merging of the television commentary and the talk at home represents a strategy to coalesce 'the watchers' and 'the spectacle'. Also, it is part of the construction of a specific 'community of practice'. (Wenger, 1998; Eckert and McConnellGinet, 1992)

"Clearly a participant role is, from the point of view of participants, not something that is unilaterally assigned, but rather jointly negotiated". (Levinson, 1988: 176) Because of unidirectionality (Klemm, 2000), the television is not able to negotiate its participant role within the talk at home. Nevertheless, the journalists' directly addressing the viewers may well be read as an invitation to join. However, it is essentially the conversationalists at home who mutually negotiate amongst themselves the status of the television in their talk. Apparently, in making the television party to their conversation, the participants make themselves part of the 'spectacle'. This implies that the 'spectacle' is no longer only the game, but that it includes the crowd as well.

The goal of people watching football on television is not really to watch television. Rather, they want to be part of the spectacle: they picture themselves on the terraces, and ultimately as team manager or one of the players. This wish is reflected in the strategy outlined above.

Coming back to Scollon's model of a watch, the following questions arise: assuming the game and the crowd are the spectacle, what is the status of the commentators, and finally, the television in general? In contrast to, e.g., the news, there seems to be another level here: the watchers, the television, the spectacle. If the audience watches the news, the programme itself is constructed by the television. It is television. In the case of a feature film, on the other hand, the television is mainly just transmitting. In the setting here, however, there is a spectacle out there, independent of television. Surely, there has been an impact of television on the significance of football. However, in the 1920s, before television became a part of every home, football was drawing the largest crowds, e.g. over 120000 for the first final played at Wembley. Referring back to the analysis above, the function of the television and specifically that of the commentators seems to be the bridging of the two sides. This holds not only for the mere technical transmission of the game (the pictures and the international sound), but also for the talk on television.

It is by going beyond the confines of the 'watchers', by taking part in the talk on television, that the spectators can move towards the 'spectacle'. Comparing televised footbail to that watched on the terraces, the following differences emerge: On the one hand, the 'watchers' in the stadium are not as separate from the spectacle as the viewers at home. Their cheering and clapping is heard. They can 'troop their colours', hold up banners etc. They can (and do) influence the spectacle up to a complete abandonment of the game. ${ }^{4}$ The 
watchers at home, on the other hand, are more removed from the spectacle. When they clap and shout, which they do (see below), they cannot be heard. However, in contrast, they have the talk on television as an additional resource and use it, possibly to compensate for that difference.

Scollon writes: "I would like to have a common framework for understanding the whole range of possible watchings from a person reading a book to a large crowd watching a football match and even including one or more watching that same match on television". (Scollon, 1998: 91) However, by subsuming these two ways of watching football, a key strategy used by the one football audience and inaccessible for the other cannot be described.

The research on fans and fandom within audience studies furnishes another explanation why a different kind of interpretation is called for with respect to fan communities:

How is the 'fan' subgroup distinguished from the larger category 'audience'?... the distinction lies in a particularly enthusiastic, even obsessive involvement with the object of fandom... coupled with a sense of community based around this shared fixation (Brooker and Jermyn, 2003: 167).

Granted, the participants in the study do not belong in that category of ardent supporters of a local team who go to every home and away match, wearing scarves etc. Their lives do not revolve around football. Still, (with the exception mentioned below) they do see themselves as football fans and with the help of the practices explained, they show their involvement with the spectacle.

As this specific participant role of the television, namely "party to the conversation at home' must be jointly negotiated by the interlocutors, this merging of the strands can only be successfully achieved if all present (or at least a sub-group) do 'watching football'. Hence, in mutually applying this strategy, they become a community of practice:

an aggregate of people who come together around mutual engagement in an endeavor. Ways of doing things, ways of talking, beliefs, values, power relations - in short, practices - emerge in the course of this mutual endeavour (Eckert and McConnell-Ginet, 1992: 464).

The contrasting behaviour of Andrew, Ursula, and their toddler is a case in point: the mutual negotiation of the television as party is never achieved so that the television remains a separate 'spectacle'. Sometimes it even only represents 'wall paper': the family interactions centre around the child so that more with-related behaviour can be found. A "with is a party of more than one whose members are perceived to be 'together". (Goffman, 1971: 19)

The corpus does not contain signs of conflict between the different needs of the spectators: namely doing 'watching football' or behaviour which relates to the group present:

One can... imagine conflict between watch-connected behaviour and with-connected 
behaviour. One of the members of the watch/with party at the movie may give dominance to the watch (primarily enjoying the movie) while the others give dominance to the with (primarily enjoying hand-holding) to the mutual irritation of both (Scollon, 1998: 93).

Hence, in this setting one could imagine somebody shouting "be quiet" or even closing the living room door. However, for once, most groups consisted only of members who actually wanted to watch the game. For the exception in the corpus, I suppose that this lack of conflict is in part due to the fact that the conversationalists know they are being taped. Generally, there is a reluctance to openly dissent and argue in front of the camera.

Another point may be that the games were aired at odd hours due to the time difference between England and Japan/Korea. Mornings, especially weekend mornings, are not traditionally football-time or television time, i.e., time reserved for the practices of that community. Rather, it is time spent with the family. For this reason, a participant watching with other family members may already interpret this as a favour and would thus refrain from asking for even more.

I can vouch for this kind of conflict from my own experience though. Quite often, when groups of friends get together to watch football, especially important games which attract people who do not normally watch, sooner or later, the group breaks up. Those who really want to watch stay in front of the television doing 'watching football'. The others who came more for the sociability either retire to a corner where they talk quietly or even leave the room. This splitting is often preceded by the loud airing of opposing views as to when and how long one should talk while watching football. Hepp shows instances of such a conflict when the 18-months-old daughter of the family disrupts the father-son-constellation of football watching. (Hepp, 1998: 164ff)

At this point in the argumentation, a few words on gender are called for. There are four women in the corpus (as opposed to seven men), and one may already view this as an indication of gender differences. However, before embarking upon an essentialist reading such as 'watching football' is male behaviour, it has to be stressed that the findings suggest the opposite. Wilma, who seems to enjoy watching football, is a full-blown member of that community of practice. She knows the rules. Together with the two male viewers, she manages to negotiate the status 'participant' for the television. There is no difference between her and the others present. Ursula, on the other hand, never does 'watching football' in the sense stated above. She looks at the television quite frequently, she also talks about what happens, but she never uses the strategies explained above. She is not doing 'watching football'. ${ }^{5}$ Thus the behaviour of the viewers cannot be accounted for in terms of gender. Rather, it is from personal interest in the game (which may well be more often found with men) and from repeatedly watching football on television with others that viewers learn these ways of doing and become members of that community of practice. The learning, however, can also be seen in this light: "in the dominant culture sport is deeply masculine, an arena to which women are admitted if they submit to its rules". (Easthope, 1986: 70). 


\section{Displaying independent knowledge}

In the following, I will present another strategy with which viewers negotiate their identities within that community of practice. In contrast to the first strategy, direct address, which may be performed on one's own, and the second strategy, which requires jointly negotiating the participant status of the television, the third strategy is characterised by yet another mechanism.

Goodwin, in an article where a group of people talks about car racing, argues that the display of 'precise independent knowledge' in the appropriate form makes participants part of "a domain of expertise and knowledge, indeed a small culture in its own right" creating that domain at the same time. (Goodwin, 1986: 289) The expertise has to be ratified by the others present. Football, in British society, surely is such a 'small culture'. As we will see, the specific setting in the corpus allows for a lot of display of that kind of knowledge due to the regulated nature of the game. The referee and the linesmen are continuously assigning a status to the game: either fair game or foul play. If they do not do anything it means that the players are following the laws of the game. In case of fouls or misconduct, the referee acts. As there is no room for middle-ground and every act (or lack of an act) by the referee is directly accessible to the spectators, potentially, a game is debatable at any time. To be able to dispute a referee's decision or, in general, to voice an opinion about a scene in a match, 'precise independent knowledge' is often a prerequisite. Viewers have to know more about football and its regulations than what is discernible from the scene, i.e. their knowledge has to be 'independent' of the immediate context.

Returning first to example 11, lines 4-6 mark the beginning of a passage that is triggered by Butt's foul. The commentator's "Butt", the referee's whistling and Darrell's "oh" overlap with the foul in the game. Darrell continues his turn with a comment "he's clobbered;" clobbering, i.e., "hitting someone very hard," (LDOCE, 2005) implies that the player committed a foul. This very same assessment is given at the same time (note the overlap line 7) by the commentator: "foul". All in all, lines $4-7$ show perfect synchronicity between the game on television, its commentary and Darrel's talk. He first spots the foul simultaneously with the referee and the commentator. Secondly, he labels it as such at the same time as the commentator (the referee really having given it away with the whistling). In doing so, Darrel displays independent knowledge: he identifies a situation as outside of the regulations and he labels it appropriately. His claim is immediately ratified both by the commentator and by the game/referee. So in this specific speech situation not only co-interlocutors but also the television can exogenously ratify statements and thus expert identities. (Drew, 1991; Gerhardt, 2006)

The display of independent knowledge often consists simply of the seemingly superfluous assignment of technical terms to scenes. A favourite in this respect is "offside". The concept of 'offside' is mildly challenging and seems to lend itself well to separate the initiated from the uninitiated. 
Example 12: BB1R offside

\begin{tabular}{|c|c|}
\hline Comm & $\begin{array}{l}\text { Roberto Carlos. } \\
\text { here is Edmilson. } \\
\text { (1.9) }\end{array}$ \\
\hline Gerard & $\begin{array}{l}\text { offside. } \\
(1.5)\end{array}$ \\
\hline Comm & he tripped one into the path of Juninho \\
\hline
\end{tabular}

In this prototypical display of independent knowledge, Gerard claims expertise by labelling a situation in the game directly when it occurs. It is characteristic that no 'information' is given. Gerard states the obvious, so his utterance has to be interpreted on the interpersonal plain. The ensuing actions by the protagonists on the pitch directly assert or disavow his reading of the scene. Again, ratification is exogenously established through the television by the game itself. As there is no controversy between the interpretation of the audience and the one presented on television, one word is sufficient in this context.

If, on the other hand, the spectator offers an interpretation which contradicts the decisions on television, the turn is often longer and accompanied by gestures. However, unlike 'dispreferreds' (Pomerantz, 1984; Sacks, 1973/87), which also have a longer marked form, here, the divergence is not mitigated but stressed. As the television does not have face wants, there is no reason to be polite for the viewers.

Example 13: EB2R yellow card surely

$\begin{array}{lll}1 & \text { Comm } & \text { free kick to England. } \\ 2 & & (2.6) \\ 3 & & \text { David Beckham will- } \\ 4 & & \text { presumably uh, } \\ 5 & & \text { (1.6tv) } \\ 6 & \text { Gerard } & \text { upff \{points at screen } \\ 7 & & \text { yellow [card } \\ 8 & & \text { surely] } \\ 9 & \text { Comm } & \text { [float this across] }\end{array}$

In the excerpt above, Gerard first makes a derogatory sound as a preface to signal his disapproval. At the same time, he points at the screen. Only then does he forward his opposing reading, namely that it should have been a yellow card and not a free kick. Another intonation unit prolongs his turn even further with the intensifier "surely". The lack of feedback though leaves it unclear whether his claim is ratified by the others. Because of the open state of talk, silence is always ambiguous.

By contrast, in the following passage, the disagreement is subsequently ratified. It illustrates how a spectator displays his knowledge about the tactics of the game. The examples 5 and 6 , in which the spectators behave like team managers, can also be read in 
this light. Hepp sees this as an instance of male style: the participants enter into a competition with the commentators on television by doing 'running commentary'. (Hepp, 1998: 161)

Example 14: EB2R he should hit

\begin{tabular}{|c|c|c|}
\hline $\begin{array}{l}1 \\
2\end{array}$ & Comm & $\begin{array}{l}\text { Sheringham. } \\
(3.2)\end{array}$ \\
\hline $\begin{array}{l}3 \\
4\end{array}$ & Gerard & $\begin{array}{l}\text { he should hit, } \\
(1.5)\end{array}$ \\
\hline 5 & Comm & all the way back to Sol [Camp]bell \\
\hline 6 & Gerard & [kh] $\{$ shakes his head $\}$ \\
\hline 7 & Jodie & $\{\mathrm{tsk}\}$ \\
\hline 8 & & they don't know what to do with it \\
\hline 9 & & the players \\
\hline 10 & & $(0.8)$ \\
\hline 11 & Comm & [he's lost it] \\
\hline 12 & Gerard & [\{shakes his head, quickly raises arms to let them fall on his knees\}] \\
\hline 13 & Comm & and BRAZIL HAVE GOT [THREE AGAINST] TWO HERE \\
\hline 14 & Gerard & [damn, \\
\hline 15 & & man.] \\
\hline
\end{tabular}

Here Gerard states what he thinks is appropriate at this specific moment in the game (line 3). In doing so he again contextualises his independent knowledge in a specific scene. Here, however, the player does not follow Gerard's suggestion (line 5). This is greeted by deprecatory interjections both by him and his wife mirroring their communal stance. Gerard's comment is subsequently ratified by his wife (lines $8-9$ ) and, exogenously, by the game itself (lines 11 and 13). His swearing (lines $14-15$ ) not only reflects his emotional involvement, but also underlines his expert status: if only they had listened to him!

To sum up, a third strategy with which interlocutors claim membership in the community of practice who gathered to do 'watching football' is the display of independent knowledge. However, only the subsequent ratification either by the television or by the interlocutors displays (for the claimant, the other viewers and the analyst) whether the expert identity has been successfully (re)established.

\section{Signalling emotions}

The transcription above leads me to a final practice observable in the corpus: the participants often air their emotions while watching the games. One instance is Gerard's swearing (lines 14 and 15) and the sounds produced (lines 6 and 7) in the passage above. Generally, a lot of sighing, audible breathing, interjections, gestures, body shifts, or 
applause accompany either particularly exciting or particularly frustrating scenes. I will refrain from giving more examples here, as a faithful transcription of these phenomena is always in need of longer explanations. Baldauf (1998) convincingly demonstrates how viewers show their emotional involvement using these strategies. Similar to the direct address in examples $4-6$, in the ATTAC corpus, these out-bursts serve multifarious functions: they help construct the identities of the viewers as ardent supporters. They are often echoed or joined by other conversationalists to build solidarity. Also, they simply help to let off steam.

\section{Conflicting identities: fan and expert}

As argued above, both displaying independent knowledge and signalling emotions are practices which reflect membership to the community of practice who does 'watching football'. However, emotions (being a fan) and knowledge (being an expert) may at times contradict each other. In the following passage this conflict becomes instantiated. England are ahead against Argentina (1:0) and there are only ten minutes to go. Michael Owen has just been replaced by a defender and England are desperately hanging on.

\section{Example 15: AE1C I can't watch it either}

\begin{tabular}{|c|c|c|}
\hline 1 & Henry & I can't watch it eit[her.] \{laughing $\}=$ \\
\hline 2 & Darrell & [no?] \\
\hline 3 & Henry & it's dreadful. \\
\hline - & & $(3.4)$ \\
\hline 5 & Darrell & well it's- \\
\hline 6 & & but it's fair, \\
\hline 7 & & I don't think Argentina deserve to lose \\
\hline 8 & & $(0.5)$ \\
\hline 8 & Henry & $\{$ coughs $\}$ \\
\hline 9 & & oh shut up Darrell, = \\
\hline 10 & Darrel & $=y a-=$ \\
\hline 11 & Wilma & $=\{$ laughs $\}=$ \\
\hline 12 & Darrell & well do you? $=$ \\
\hline 13 & & $=\mathrm{I}$ mean $-=$ \\
\hline 14 & Wilma & $=\{$ laughs $\}$ \\
\hline 15 & & $(1.3)$ \\
\hline 16 & Wilma & I know, $=$ \\
\hline 17 & & $=\mathrm{I}-\mathrm{I}$ think- $=$ \\
\hline 18 & Henry & $=$ believe we're being [totally fair.] $=$ \\
\hline 19 & Wilma & {$[\mathrm{I}-\mathrm{I}-\mathrm{-}$} \\
\hline 20 & Darrell & $=$ yeah \\
\hline
\end{tabular}

The first three lines represent the closing sequence of a longer exchange where all three 
spectators agree that the situation is unbearable. England are playing so poorly that they fear a goal of the Argentines at any time. Their talk is full of emotions, they construct themselves as fans. Then, after a pause of 3.4 seconds, Darrell restarts the conversation using a discourse marker to renegotiate the background to his succeeding utterance (line 5). Jucker attests this function of "well" to mark a "shift in the relevant context... because there is a change in perspective". (Jucker, 1993: 451) Darrell does not seem satisfied with the beginning; he breaks off and starts anew replacing "well" with "but" (line 6). This brings out the idea of contrast more strongly, namely that Darrell is going to oppose what has been negotiated by the participants up until that moment. Jucker also states that the situations in which "well" is used often involve face-threats to other participants. (Goffman, 1967; Brown and Levinson, 1987) In the following, we will see that it is not so much a threat to the "face', "the public self-image" of one of the participants, but rather that Darrell's statement highlights a fissure in the construction of the community of practice. On the one hand, participants have to show that they are football experts, and on the other hand, they have to be ardent supporters. At times, however, these represent mutually exclusive standpoints or conflicting schemas.

The subsequent turns illustrate that Darrell did well in preparing his interlocutors for contrast: his saying "I don't think Argentina deserve to lose" (line 7) opposes their mutual standpoint that they had just negotiated, namely that Argentina should not shoot a goal in this situation. Also, he contradicts what a football fan is supposed to wish in general, namely that the opposing team always lose. Darrell here changes his stance from that of a fan to that of a neutral football expert. He now abides to the maxim "May the better team win!" For this particular game, it would indicate a draw.

After a short delay (0.5 seconds) typical for contradiction (Pomerantz,1984; Sacks, 1973/1987), this change of standpoint triggers first coughing by his friend (line 5) and then a reprimand: "oh shut up Cyril". Wilma starts laughing (lines 11 and 14), which may indicate a clash of frames. (Norrick, 1986 and 1993) In line 12, Darrell repeats his use of "well" to further stress that he shifted his standpoint. With "do you," a delayed questiontag to line 7, he tries to secure support from his co-watchers. He finishes with a hedge again adding a degree of non-commitment and uncertainty to his utterance (line 13).

After this transitional period marked by the coughing, laughter and Darrell's careful signalling of a shift in perspective, Wilma, in lines 16-17, finally shows her support and Henry summarizes the new standpoint: they are now "being totally fair" (line 18). Thus, the participants have negotiated with some difficulty that they are now positioning themselves as 'football experts' against the game and no longer as 'supporters'.

This passage illustrates that strategies used within a community of practice may be contradictory. When such a conflict becomes instantiated, it needs careful negotiation on the part of all interlocutors to reframe their identities.

\section{Conclusion}

A close analysis of the ATTAC corpus gives an account of how the television is used to 
negotiate identities and membership in that specific community of practice which does 'watching football on television'. Some of the practices such as direct address or emotional outbreak can be performed by single viewers. However, most strategies such as the display of independent knowledge need ratification to be interpretable as tokens of a successful negotiation of identity. To make the television become party to the conversation at home, or rather, to become party to the talk on television, mutual negotiation of all present is a prerequisite. Being able to predict gaps in the game or to project the completion points of the commentators' turns can only be learnt through watching football on television. In doing that, in learning the particular ways of doing and ways of talking, the community of practice constitutes itself. As most of the strategies only function in a group of other aficionados, it also becomes clear why it is more pleasurable to watch football amongst equals.

The claim put forth by media studies that fans constitute a special subgroup within the audience is corroborated by this study: fans do indeed differ in their reception from other non-fans watching the same programme in the ATTAC corpus. In order to generalise this finding, however, a larger corpus containing other fan-groups (e.g. Star Trek fans) would be desirable.

Scollon's notion of a 'watch' with the two sides 'watcher' and 'spectacle' seems mainly applicable in those cases where a non-supporter watches. For this specific community of practice, a three part model is more fitting. Scollon argues: "One does not mind a discourse in which one is identified as someone who watches football games around the house if one is getting a good free game without the messes of travel and bad weather". (1998: 154) However, the ATTAC corpus suggests the opposite. The football fans who do "watching football' strive to become part of the spectacle with the help of the practices described in this study. They seem not to want to be identified as people who watch at home, but as part of the spectacle. The spectacle would then consist not only of the game, but also of the crowd. The talk on television works as a bridge between the watchers and the spectacle. This shows that more research is called for to discover the strategies of different communities of practice that are all subsumed under 'watchers'. One starting point may be close analyses of the talk of spectators watching other television genres, like e.g. the news, or fictional or narrative genres like soap operas or feature films.

A field only adumbrated in this article is how the spectators negotiate the meaning of the primary media text. It has partly been dealt with in that the ratification of expert claims might presuppose agreement about the meaning. However, a close analysis of interactions about the meaning of different scenes in the game (i.e. the pictures on television) and about the faithfulness of the commentators' assessment (i.e. the talk on television) seem important to gain further insight into the appropriation of media discourse.

By moving closer to the audience, I hope to have illustrated how spectators actively use the television. The helpless victim of early spectator studies cannot be found in the corpus. A close analysis of the interplay between the primary media text and the talk at home yields the strategies with which the community of practice who does 'watching football on television' uses the television to mutually negotiate membership and identities. 
Notes

1. Comm is short for commentator. The pundit, also referred to as the co-commentator or summariser, is similar to the American color commentator.

2. The intervening twelve seconds contain too many incomprehensible parts to be used for analysis.

3. IS, short for international sound, refers to the sounds directly recorded in the stadium.

4. Later in his monograph, Scollon subsumes football matches watched in the stadium under the game model because "it seems to me to be stretching things to talk about messages being sent by the players to the fans or vice versa". (1998: 151) As I am not concerned with this type of setting here, a few remarks shall suffice. There are 'messages sent' in both directions, at least in European football. To give just one example, the songs constitute permanent feedback to the teams. I have demonstrated elsewhere how fans, with the help of three songs, expressed their acceptance of a player (curiously after a penalty miss) who until then was hated by everybody because he had changed from the local rival. (Gerhardt, 2000)

5. For the other two women the status remains unclear. Both are often incomprehensible or inaudible on the tapes, so that I would not venture to draw any conclusions from the little talk in the corpus.

\section{References}

Adorno, Theodor W. and Max Horkheimer (1947): Dialectic of Enlightenment. London: Verso. Ang, Ien (1985): Watching Dallas. Soap Opera and the Melodramatic Imagination. London: Methuen.

Baldauf, Heike (1998): “Aufschreien und Stöhnen. Äußerungsformen emotionaler Beteiligung beim Fernsehen". In A. Brock and M. Hartung, eds., Neuere Entwicklungen in der Gesprächsforschung. Vorträge der 3. Arbeitstagung des Pragmatischen Kolloquiums Freiburg. Tübingen: Narr, 37 - 54.

. (2001): "Strukturen und Formen des fernsehbegleitenden Sprechens". In W. Holly, U.

Püschel, and J. Bergmann, eds., Der sprechende Zuschauer. Wie wir uns Fernsehen kommunikativ aneignen. Wiesbaden: Westdeutscher Verlag, 61-82.

Beck, Christina (1995): "You make the call. The co-creation of media text through interaction in an interpretive community of 'Giant fans'". The Electronic Journal of Communication/La Revue Electronique de Communication 5.

Brooker, Will and Deborah Jermyn (eds.)(2003): The Audience Studies Reader. London, England: Routledge.

Brown, Penelope and Stephen C. Levinson (1987): Politeness. Some Universals in Language Usage. Cambridge: Cambridge University Press.

Chafe, Wallace and Jane Danielewicz (1987): "Properties of spoken and written language". In R. Horowitz and S. J. Samuels, eds., Comprehending Oral and Written Language. San Diego: Academic Press, 83-113.

Cruttenden, Alan (1986): Intonation. Cambridge: Cambridge University Press. de Certeau, Michel (1980): L'invention du Quotidien. Vol. 1, Arts de faire. Paris: Gallimard. Drew, Paul (1991): "Asymetries of knowledge in conversational interactions" In I. Markova and K. Foppa, eds., Asymmetries in Dialogue. Hemel Hempstead: Harvester Wheatsheaf. 
Easthope, Anthony (1986): What a Man's Gotta Do. Masculine Myth in Popular Culture. London: Paladin.

Eckert, Penelope and Sally McConnell-Ginet (1992): "Think practically and look locally. Language and gender as community-based practice". Annual Review of Anthropology 21: 461-490.

Fish, Stanley (1980): Is There a Text in this Class? The Authority of Interpretive Communities. Cambridge: Harvard University Press.

Fiske, John (1987): Television Culture. London: Routledge.

Gerhardt, Cornelia (2000): “'Wir scheißen auf den BvB.' Fangesänge im Fußballstadion”. Paper presented at the Kolloquium Englische Sprachwissenschaft und Deutsche Sprachwissenschaft, Saarland University, Saarbrücken, unpubl. MS.

. (2006): "The negotiation of expertise in symmetrical talk". Paper presented at the ICCA 06, International Conference on Conversation Analysis, Helsinki, unpubl. MS.

Goffman, Erving (1967): Interaction Ritual. Essay on Face to Face Behavior. Garden City: Anchor.

(1971): Relations in Public. Microstudies of the Public Order. New York: Basic. (1981): Forms of Talk. Philadelphia: University of Pennsylvania Press.

Goodwin, Charles (1986): "Audience diversity, participation and interpretation". Text 6(1): 283-316.

Hall, Stuart (1980): "Encoding/decoding". In S. Hall, D. Hobson, A. Lowe, and P. Willis, eds., Culture, media, language. London: Hutchinson, 128-138.

Hepp, Andreas (1998): Fernsehaneignung und Alltagsgespräche. Mediennutzung aus der Perspektive der Cultural Studies. Wiesbaden: Westdeutscher Verlag.

Hoggart, Richard (1957): The uses of literacy. Harmondsworth, Penguin.

Holly, Werner, Ulrich Püschel, and Jörg Bergmann (eds.)(2001): Der sprechende Zuschauer. Wie wir uns Fernsehen kommunikativ aneignen. Wiesbaden: Westdeutscher Verlag.

Jucker, Andreas H. (1993): "The discourse marker 'well': A relevance theoretical account". Journal of Pragmatics 19: 435-452.

Jefferson, Gail ((1972): "Side sequences". In D.N. Sudnow, ed., Studies in Social Interaction. New York: Free Press, 294-338

Klemm, Michael (2000): Zuschauerkommunikation. Formen und Funktionen der alltäglichen kommunikativen Fernsehaneignung. Frankfurt: Lang.

(2001): "Themenbehandlung". In W. Holly, U. Püschel, and J. Bergmann, eds., Der sprechende Zuschauer. Wie wir uns Fernsehen kommunikativ aneignen. Wiesbaden: Westdeutscher Verlag, 115-142.

Lazarfeld, Paul F., Bernard R. Berelson, and Hazel Gaudet (1944): The People's Choice. How the Voter Makes up his Mind in a Presidential Campaign. New York: Columbia University Press. Levinson, Stephen C. (1983): Pragmatics. Cambridge: Cambridge University Press.

. (1988): "Putting linguistics on a proper footing: Explorations in Goffman's concepts of participation". In P. Drew und A. Wotton, eds., Erving Goffman. Exploring the Interaction Order. Oxford: Polity Press, 161-227.

Liebes, Tamar and Elihu Katz (1990): The Export of Meaning. Cross-Cultural Readings of Dallas.

Cambridge: Polity Press.

Livingstone, Sonia M. (1990): Making Sense of Television. Oxford: Pergamon

Longman Dictionary of Contemporary English. Fourth Edition. (2005) Harlow: Pearson. 
Matthewson, Lisa (1992): "Talking to the TV. The conversation behaviour of television viewers". Wellington Working Papers in Linguistics 5: 17-35.

Morley, David (1980): The Nationwide Audience. London: British Film Institute.

Mulvey, Laura (1975): "Visual pleasure and narrative cinema". Screen 16(3): 6-18.

Norrick, Neal R. (1986): "A frame-theoretical analysis of verbal humor. Bisociation as schema conflict". Semiotica 60: 225-245. . (1993): Conversational Joking. Bloomington: Indiana University Press.

Pomerantz, Anita (1984): "Agreeing and disagreeing with assessments. Some features of preferred/dispreferred turn shapes". In J.M. Atkinson and J.C. Heritage, eds., Structures of Social Action. Cambridge: Cambridge University Press, 57-101.

Radway, Janice A. (1984): Reading the Romance. Women, Patriarchy and Popular Literature. Chapel Hill: University of North Carolina Press.

Sacks, Harvey (1973/1987): "On the preferences for agreement and contiguity in sequences in conversation”. In G. Button \& J.R.E. Lee, eds., Talk and Social Organization. Clevedon: Multilingual Matters, 54-69.

Sacks, Harvey, Emanuel A. Schegloff and Gail Jefferson (1974): “A simplest systematics for the organization of turn-taking for conversation”. Language 50(4): 696-735.

Schegloff, Emanuel A. and Harvey Sacks (1973): "Opening up closings". Semiotica 8(4): 289-327.

Scollon, Ron (1998): Mediated Discourse as Social Interaction. A Study of News Discourse. London: Longman.

Staiger, Janet (1992): Interpreting films: Studies in the Historical Reception of American Cinema. Princeton: Princeton University Press.

Tannen, Deborah (1984): Conversational Style: Analyzing Talk among Friends. Norwood: Ablex. Wenger, Etienne (1998): Communities of Practice. Learning, Meaning and Identity. Cambridge: Cambridge University Press.

Wertham, Frederic (1955): Seduction of the Innocent. London: Museum Press.

Winick, Charles (1963): "Tendency systems and the effects of a movie dealing with a social problem". Joumal of General Psychology 68: 289-305.

\section{Appendix}

Transcription conventions:

she's out.

oh yeah?

so,

bu- but

DAMN

(2.0)

[and so-]

[WHY] her?

and $=$

$=$ then

(?)

\{laughs\} falling tone in the preceding element; suggesting finality rising tone in the preceding element; cf. yes-no question intonation level, continuing intonation; suggesting non-finality a cutoff or truncated intonation unit high pitch and a rise in volume. timed pauses in seconds $\left({ }^{\mathrm{t}}\right.$ on televsion) overlapping talk

latching

incomprehensible parts para- and non-verbal behaviour and contextual information 